\title{
Common Cytoplasmic Antigen in Five Acholeplasma Species
}

\author{
GABRIEL Y. LEE AND GEORGE E. KENNY* \\ Department of Pathobiology, University of Washington School of Public Health and Community Medicine, \\ Seattle, Washington 98195
}

\begin{abstract}
Two-dimensional immunoelectrophoresis was used to study the antigenic composition and serological relationships of the following five Acholeplasma species: Acholeplasma axanthum, Acholeplasma equifetale, Acholeplasma granularum, Acholeplasma hippikon, and Acholeplasma laidlawii. A total of 15 to 25 precipitin peaks were observed in the homologous reactions. A. equifetale and $A$. hippikon were most closely related serologically, having six related antigens. Nearly all antigens were negatively charged at $\mathrm{pH} 8.6$; the only exceptions were one antigen of $A$. axanthum and one antigen of $A$. laidlawii. The "positively charged" antigens were membrane associated and did not cross-react. One common antigen was recognized in each organism by all heterologous antisera. Monospecific antiserum prepared against the common antigen (peak 0.72 of $A$. hippikon) reacted with one antigen in each species tested. The electrophoretic mobilities of the common antigen ranged from $0.45(A$. axanthum $)$ to $0.72(A$. hippikon). This antigen was located in the cytoplasm of $A$. laidlawii because the antiserum reacted only with the cytoplasmic fractions, not with the membrane fractions. The recognition of a common cytoplasmic antigen in the Acholeplasmataceae is important to the taxonomy of these organisms.
\end{abstract}

The organisms classified in the genus Acholeplasma are presently separated into a number of species, including Acholeplasma axanthum, Acholeplasma equifetale, Acholeplasma granularum, Acholeplasma hippikon, Acholeplasma laidlawii, Acholeplasma modicum, Acholeplasma morum, and Acholeplasma oculi, on the basis of serological distinctions and a limited number of biochemical and physiological differences (18). Double-immunodiffusion studies of the Acholeplasma species have shown that these organisms have one or more common antigens $(8,9)$. However, the double-immunodiffusion technique is relatively insensitive, and neither antigens nor antibodies can be quantitated (8).

In this study, we used the two-dimensional immunoelectrophoretic method of Laurell (11) to study the antigenic composition and serological relationships of five of the seven Acholeplasma species because of its great sensitivity and resolving power. A monospecific antiserum against one antigen common to the genus was prepared and was used to identify the common antigen in the various species.

\section{MATERIALS AND METHODS}

Organisms. Five Acholeplasma species (18) were used in this study. The following three strains were obtained from the American Type Culture Collection: A. equifetale ATCC $29724^{\mathrm{T}}$ (type strain), A. hippikon ATCC $29725^{\mathrm{T}}$, and $A$. laidlawii ATCC 14192. $A$. axanthum S-743 and A. granularum Friend were gifts from J. G. Tully (18). Each species was filter-cloned on agar plates (6) three times in our laboratory, and the resulting clones were used throughout this study.

Preparation of antigens. Organisms were grown in "hot" soy-peptone-yeast extract dialysate broth (14) supplemented with $2 \%$ (vol/vol) agamma horse serum (Alpha Gamma Labs, Sierra Madre, Calif.), $5 \mathrm{mM}$ glucose, $100 \mathrm{U}$ of penicillin per $\mathrm{ml}$, and $10 \mathrm{mM} \mathrm{N}$ tris(hydroxymethyl)methyl-2-aminoethanesulfonic acid (TES) buffer at a final $\mathrm{pH}$ of 7.3. The inoculum was $0.1 \mathrm{ml}$ of an actively growing culture per $700 \mathrm{ml}$. Cultures were incubated at $37^{\circ} \mathrm{C}$ for 1 to 2 days until a fine haze was observed. Cells were harvested by centrifugation at $13,200 \times g$ for $30 \mathrm{~min}$, washed three times in TES-saline $(0.15 \mathrm{M} \mathrm{NaCl}, 10 \mathrm{mM}$ TES, pH 7.3), and finally suspended in distilled water and stored at $-70^{\circ} \mathrm{C}$ until they were used. Protein concentrations were measured by the method of Lowry et al. (12) and were adjusted to $2 \mathrm{mg} / \mathrm{ml}$.

Preparation of immunogens. Cells were grown as they were for the preparation of antigens (see above), except that a gamma rabbit serum was used instead of agamma horse serum. To minimize the risk of crosscontamination, immunogens were prepared from organisms that had been subcultured less than six times since their arrival in our laboratory. A 2-liter culture was grown for each species, and the concentrated cells were suspended in $10 \mathrm{ml}$ of TES-saline. The protein content of each immunogen was 1 to $2 \mathrm{mg} / \mathrm{ml}$, as determined by the method of Lowry et al.

Preparation of antisera. The immunization procedure used to prepare antisera to whole organisms has been described previously (7). Briefly, 2 to $5 \mathrm{mg}$ of protein was emulsified with an equal volume of Freund 
incomplete adjuvant and injected intramuscularly into each New Zealand white rabbit. After 3 weeks a series of four booster shots containing increasing dosages $(0.1,0.2,0.3$, and $0.4 \mathrm{ml}$ of the immunogen without adjuvant) were administered intravenously at 3- to 4day intervals. The animals were bled by cardiac puncture 7 days after the last immunization. Antisera to bovine serum albumin and agamma horse serum were prepared in rabbits by using the same immunization scheme.

Preparation of membrane and cytoplasmic fractions. Cells from a 2-liter culture were harvested before the end of the logarithmic phase of growth (as estimated from the growth curve) and washed three times in TES-saline, and the resulting pellet was injected into $100 \mathrm{ml}$ of distilled water preheated to $37^{\circ} \mathrm{C}$ and incubated for $30 \mathrm{~min}$ at $37^{\circ} \mathrm{C}(15)$. The osmotically lysed cells were centrifuged at $13,200 \times g$ for $15 \mathrm{~min}$ to remove unbroken cells. The membranes were sedimented by centrifugation at $34,000 \times g$ for $60 \mathrm{~min}$, and the supernatant was concentrated by centrifugation in Amicon Centriflo membrane cones (type CF25); this preparation was designated the cytoplasmic fraction. The sedimented membranes were washed three times in $0.25 \mathrm{M} \mathrm{NaCl}$ and then suspended in distilled water. The membrane and cytoplasmic fractions were adjusted to protein concentrations of $2 \mathrm{mg} / \mathrm{ml}$ in distilled water.

Solubilization of antigens. Antigen preparations were solubilized with $1 \%(\mathrm{vol} / \mathrm{vol})$ Triton $\mathrm{X}-100$. We observed no difference in the antigenic profiles when the antigens were incubated with the detergent for 15,30 , and $60 \mathrm{~min}$ at $37^{\circ} \mathrm{C}$; therefore, all antigen samples used in this study were incubated with detergent for $15 \mathrm{~min}$. Triton X-100 $(0.5 \%)$ was also incorporated into the agarose gel in both dimensions of electrophoresis in order to maintain the solubility of the components and to avoid distortion of peaks.

Two-dimensional immunoelectrophoresis. We used the two-dimensional immunoelectrophoresis technique of Laurell (11), as adapted by Thirkill and Kenny (16). Briefly, agarose-precoated glass slides ( 4.3 by 4.3 $\mathrm{cm}$ ) were coated with $3.0 \mathrm{ml}$ of supporting matrix, which consisted of $0.5 \%$. (vol/vol) agarose (SeaKem agarose; Marine Colloids, Rockland, Maine) with an electroendosmosis value $\left(-m_{r}\right)$ of 0.16 to $0.19,0.5 \%$ (vol/vol) Triton $\mathrm{X}-100$, and $0.01 \%(\mathrm{wt} / \mathrm{vol})$ sodium azide in barbital buffer $(\mathrm{pH} 8.6$; ionic strength, 0.05$)$. After antigen samples were incubated with Triton X100 for $15 \mathrm{~min}$ at $37^{\circ} \mathrm{C}$, they were sonicated in an ice bath for $1 \mathrm{~min}$ with an interruption every $15 \mathrm{~s}$ in order to prevent overheating. Then $10 \mu \mathrm{l}$ of antigen $(20 \mu \mathrm{g}$ of protein) and $2 \mu \mathrm{l}$ of bovine serum albumin $(5 \mathrm{mg} / \mathrm{ml})$ were added to the well. First-dimension electrophoresis was performed for $60 \mathrm{~min}$ at $6 \mathrm{~V} / \mathrm{cm}$, as measured directly on the agarose. Second-dimension electrophoresis was carried out for $16 \mathrm{~h}$ at $1.5 \mathrm{~V} / \mathrm{cm}$ with 0.1 to $0.5 \mathrm{ml}$ of antiserum in the second-phase gel (total volume, $2 \mathrm{ml}$ ). After electrophoresis, the slides were washed in TES-saline for $24 \mathrm{~h}$ and in distilled water for $4 \mathrm{~h}$ and then air dried in an incubator at $37^{\circ} \mathrm{C}$ overnight. Immunoprecipitin peaks were stained with $0.5 \%$ (wt/vol) Coomassie brilliant blue R-250 (Bio-Rad Laboratories, Richmond, Calif.) dissolved in a solvent consisting of $45 \%(\mathrm{vol} / \mathrm{vol})$ ethanol and $10 \%(\mathrm{vol} / \mathrm{vol})$ glacial acetic acid. Destaining was done with solvent alone.
Helenius and Simons (5) have shown that charge shift electrophoresis can be used to distinguish between amphiphilic and hydrophilic proteins. The adaptation of this procedure to two-dimensional immunoelectrophoresis described by Alexander and Kenny (1) was used to discriminate between cytoplasmic and membrane antigens because amphiphilic proteins (presumably membrane associated) show a distinct increase in mobility relative to bovine serum albumin. In practice, $0.1 \%(\mathrm{wt} / \mathrm{vol})$ sodium deoxycholate was added to an agarose gel which also contained $0.5 \%$ (vol/ vol) Triton X-100 in the first dimension of electrophoresis. No sodium deoxycholate was incorporated into the second-dimension gel, which contained the antiserum. After electrophoresis, the slides were washed, dried, and stained as described above.

Immunoelectrophoresis. Agarose-precoated microscope slides ( 25 by $75 \mathrm{~mm}$ ) were coated with $2.5 \mathrm{ml}$ of the same supporting matrix that was used for twodimensional immunoelectrophoresis and then cut (see Fig. 1). A $3-\mu \mathrm{l}$ amount (6 $\mu \mathrm{g}$ of protein) of antigen was added to the well (diameter, $2 \mathrm{~mm}$ ) and was electrophoresed for $18 \mathrm{~min}$ at $8 \mathrm{~V} / \mathrm{cm}$. A $50-\mu \mathrm{l}$ amount of homologous antiserum was added to the trough, and precipitin arcs were allowed to develop in a moist chamber for $48 \mathrm{~h}$ at room temperature. The slides were then washed in TES-saline and distilled water and stained with Coomassie brilliant blue as described above for two-dimensional immunoelectrophoresis.

Preparation of monospecific antiserum. The method used to prepare monospecific antiserum in rabbits has been described previously (4). Triton X-100-solubilized A. hippikon antigen $(20 \mu \mathrm{g})$ was electrophoresed in the first dimension and precipitated in the second dimension of electrophoresis with antiserum to $A$. laidlawii (concentration, $10 \%$ ), so that the precipitin line to be excised was distinct and clearly separated from other precipitates. After electrophoresis, the slides were washed in TES-saline for $24 \mathrm{~h}$ and then in distilled water for $24 \mathrm{~h}$ to ensure that all unprecipitated protein was removed. The tip of precipitin peak 0.72 (see Fig. 2, slide B3) was excised from 20 immunoelectrophorograms. One-half of the immunoprecipitated material was suspended in $1 \mathrm{ml}$ of phosphate-buffered saline and emulsified with $1 \mathrm{ml}$ of Freund complete adjuvant. This mixture was injected intradermally at multiple sites in both the nuchal and inguinal regions of rabbits. After 3 weeks, $50 \mathrm{ml}$ of blood was drawn from each rabbit. The remaining one-half of the immunoprecipitated material was suspended in $1 \mathrm{ml}$ of phosphatebuffered saline, emulsified with $1 \mathrm{ml}$ of Freund incomplete adjuvant, and then injected into a rabbit intramuscularly. After 2 weeks six additional bleedings $(50 \mathrm{ml}$ each) were done at 3 - to 4-day intervals, and the rabbit was bled by cardiac puncture 2 weeks after the final $50-\mathrm{ml}$ bleeding.

\section{RESULTS}

Immunoelectrophoresis. In order for an antigen to be identified by two-dimensional immunoelectrophoresis, the antigen must be negatively charged at $\mathrm{pH} 8.6$ so that it migrates toward the anode in both phases. Therefore, Triton X100-solubilized antigens of the five Acholeplasma species were tested by immunoelectro- 


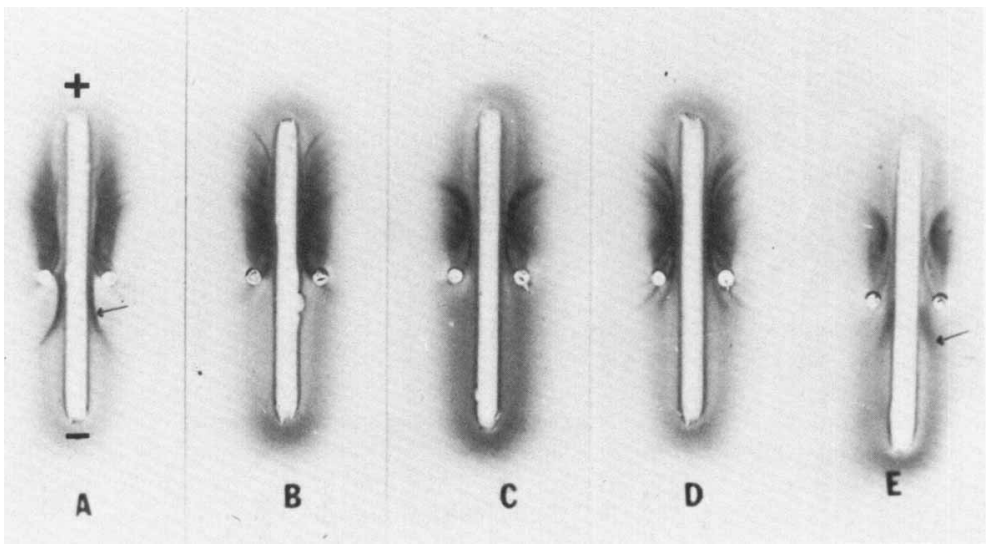

FIG. 1. Immunoelectrophoretic separation of Acholeplasma antigens in agarose gels. Troughs contained only homologous antisera. Gel A, A. axanthum antigen; gel B, A. equifetale antigen: gel C, $A$. granularum antigen; gel D, A. hippikon antigen; gel E, A. laidlawii antigen. The arrows indicate the positively charged antigens.

phoresis with their homologous antisera. With the exception of one antigen of $A$. axanthum and one antigen of $A$. laidlawii, all antigens migrated toward the anode (Fig. 1). Therefore, we concluded that two-dimensional immunoelectrophoresis is a feasible technique for studying the antigenic compositions of Acholeplasma species, bearing in mind that at least one antigen of $A$. axanthum and one antigen of $A$. laidlawii had apparent positive charges at $\mathrm{pH}$ 8.6. These antigens are called "positively charged" even though we realize that electroendosmotic drift was responsible for most of their cathodal movement.

Antigenic profiles determined by two-dimensional immunoelectrophoresis. When antigens of the five species were tested against their homologous antisera, 15 to 25 precipitin peaks were observed (Fig. 2). Homologous reactions showed 15 to 25 precipitin peaks, in contrast to the 1 to 6 peaks obtained in the heterologous reactions (Table 1). A. equifetale and $A$. hippikon were most closely related serologically, having six related antigens. One common antigen was recognized in each organism by all heterologous antisera (Table 1). Antiserum prepared against $A$. axanthum reacted with two antigens in each of the other four species tested (Fig. 2). With the A. equifetale, A. granularum, and $A$. laidlawii antigens, these two antigens were superimposed on each other, with one extending beyond the other. The relative electrophoretic mobilities (compared with bovine serum albumin) of the two superimposed antigens were similar and were $0.47,0.50$, and 0.63 for $A$. equifetale, $A$. granularum, and $A$. laidlawii, respectively, whereas those of the two antigens of $A$. hippikon differed (relative mobilities, 0.72 and 0.57 ). These cross-reacting anti- gens, as well as their characteristic electrophoretic mobilities, were also revealed when the antigens were tested with other antisera (Fig. 2).

Positively charged antigens. Antigens of the various species were run against their homologous antisera in two-dimensional immunoelectrophoresis tests but with the polarity of the current reversed in both phases (i.e., with the anode on the right in the first phase and at the bottom in the second phase). When this technique was used, as was the case for immunoelectrophoresis, only $A$. axanthum and A. laidlawii showed positively charged antigens. The precipitin peak of $A$. axanthum stained intensely (Fig. 3 ), suggesting that the antigen was present in a relatively large amount. When the antigen well was placed near the center of the slide with antiserum present in the areas above and below the antigen well, the positively charged antigens had similar electrophoretic mobilities $(-0.10$ for A. laidlawii and -0.11 for $A$. axanthum) compared with bovine serum albumin (Fig. $3 \mathrm{C}$ and D). However, the positively charged antigens from A. axanthum and A. laidlawii were serologically distinct because no cross-reaction was observed. To determine whether the positively charged antigen was membrane associated or cytoplasmic, membrane and cytoplasmic fractions of $A$. laidlawii were tested. Only the membrane fraction had the positively charged antigen. Charge shift immunoelectrophoresis with $A$. axanthum and $A$. laidlawii antigens also suggested that the positively charged antigens were membrane associated.

Demonstration of a common antigen in Acholeplasmataceae by using monospecific antiserum. Monospecific antiserum prepared against peak 0.72 of A. hippikon (developed against $A$. laidlawii antiserum [Fig. 2, frame B3]) was tested 


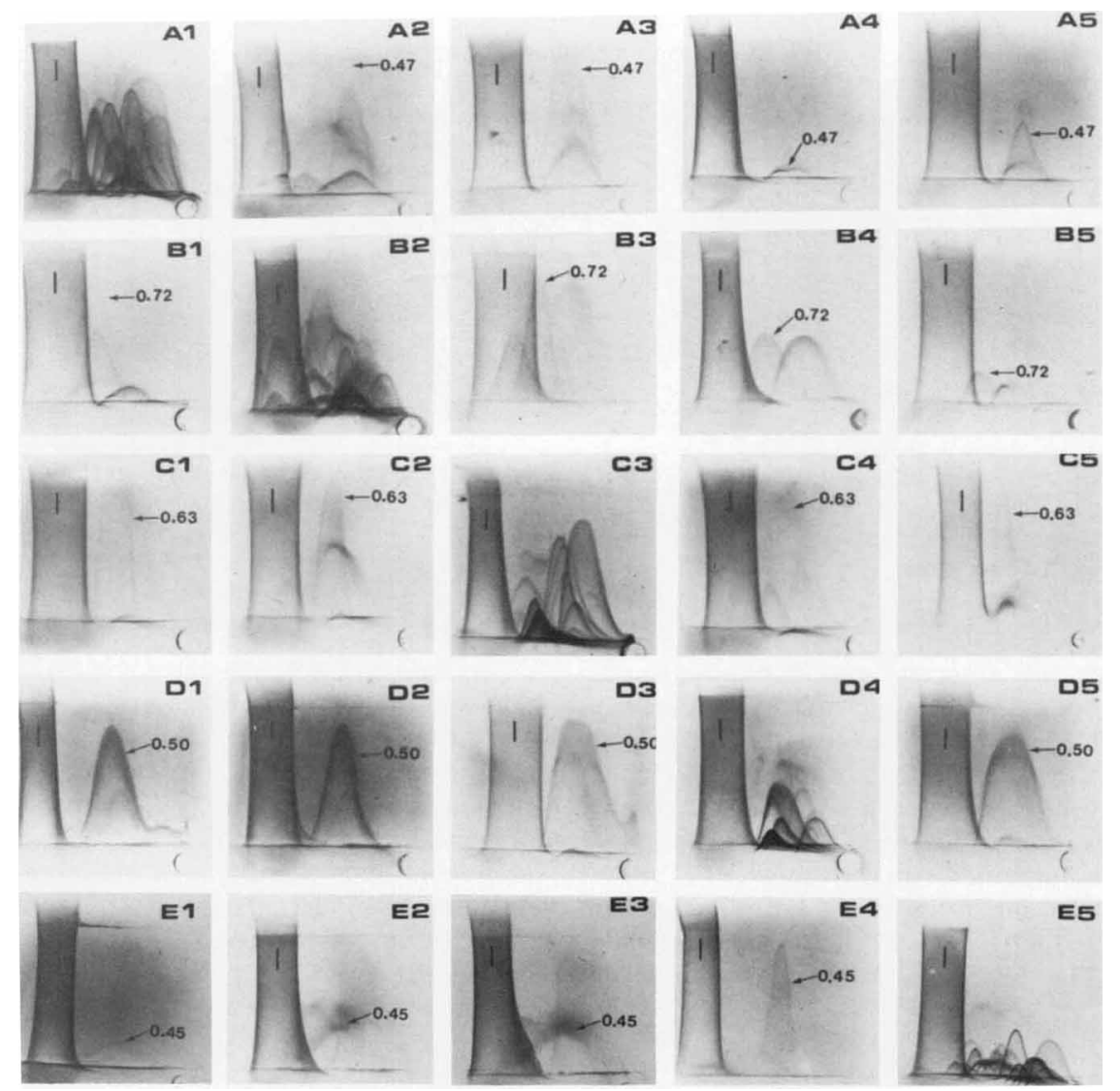

FIG. 2. Serological comparison of five Acholeplasma species by two-dimensional immunoelectrophoresis. Antigens: (A) A. equifetale; (B) A. hippikon; (C) A. laidlawii; (D) A. granularum; and (E) A. axanthum. Antisera: (1) A. equifetale; (2) A. hippikon; (3) A. laidlawii; (4) A. granularum; and (5) A. axanthum. Antiserum was used at a concentration of $10 \%(\mathrm{vol} / \mathrm{vol})$. The vertical bar at the top left corner of each frame indicates the center of the bovine serum albumin control pillar. The arrows indicate the common antigen recognized by the monospecific antiserum. The anode was to the left and top of figure.

against antigens from the various species. One precipitin peak was observed in all of the species. However, the antigenic components recognized by the monospecific antiserum did not have similar electrophoretic mobilities. The relative electrophoretic mobilities of the antigens (Fig. 2) were as follows: $A$. axanthum, $0.45 ; A$. equifetale, 0.47; A. granularum, 0.50; A. hippikon, 0.72 ; and $A$. laidlawii, 0.63 . To be certain that these antigens from the different species were indeed serologically related, equal quantities of antigens ( $20 \mu \mathrm{g}$ of protein) of $A$. hippikon and $A$. laidlawii were placed in the same antigen well and tested with the monospecific antiserum (Fig. 4). The double peak recognized by the monospecific antiserum in $A$. hippikon antigen was consistently observed (Fig. 4B), and we did not know whether two related antigens or two different antigens were present. However, the leading edge of the combined precipitin peaks fused (Fig. 4C), indicating that the two antigens in the two different organisms were related and that the two peaks observed in $A$. hippikon were related as well (10).

Cytoplasmic location of the common antigen. To determine whether the common antigen was located in the membrane or in the cytoplasm, membrane and cytoplasmic fractions of $A$. laidlawii were tested with the monospecific antiserum. Only the cytoplasmic fraction reacted with the antiserum, indicating that the common antigen was located in the cytoplasmic fraction of $A$. laidlawii. When antigens from the different species were tested against the antiserum by charge shift two-dimensional immunoelectrophoresis, none of the precipitin peaks was shifted by incorporation of sodium deoxycholate in the agarose gel in the first phase, suggesting that the cross-reacting antigen was hydrophilic and probably cytoplasmic. 
TABLE 1. Serological comparison of five Acholeplasma species and agamma horse serum by twodimensional immunoelectrophoresis

\begin{tabular}{|c|c|c|c|c|c|c|}
\hline \multirow[b]{2}{*}{ Antigens } & \multicolumn{6}{|c|}{ Antiserum $^{a}$} \\
\hline & $\begin{array}{c}A . \\
\text { equifetale }\end{array}$ & $\begin{array}{c}\text { A. } \\
\text { hippikon }\end{array}$ & $\begin{array}{c}A . \\
\text { laidlawii }\end{array}$ & $\begin{array}{c}\text { A. } \\
\text { granularum }\end{array}$ & $\begin{array}{c}\text { A. } \\
\text { axanthum }\end{array}$ & $\begin{array}{c}\text { Agamma } \\
\text { horse } \\
\text { serum }\end{array}$ \\
\hline A. equifetale & $21^{h}$ & 6 & 4 & 2 & 2 & 0 \\
\hline A. hippikon & 6 & $25^{b}$ & 3 & 2 & 2 & 0 \\
\hline A. laidlawii & 3 & 4 & $17^{h}$ & 4 & 2 & 0 \\
\hline A. granularum & 2 & 3 & 4 & $15^{h}$ & 2 & 0 \\
\hline A. axanthum & 1 & 3 & 3 & 2 & $20^{h}$ & 0 \\
\hline $\begin{array}{l}\text { Agamma horse } \\
\text { serum }\end{array}$ & 0 & 0 & 0 & 0 & 0 & $12^{b}$ \\
\hline
\end{tabular}

${ }^{a}$ Antigens were used at a concentration of $20 \mu \mathrm{g}$ of protein per slide and were tested with $10 \%(\mathrm{vol} / \mathrm{vol})$ antiserum. The numbers are the numbers of precipitin peaks which could be clearly distinguished on the twodimensional electrophorograms.

${ }^{b}$ Homologous reactions.

Evidence for a second common antigen. To determine whether the superimposed antigens in A. laidlawii (Fig. 5A) were serologically distinct, a suppression experiment was done (2), in which electrophoretically separated antigens of $A$. laidlawii were run into the second-phase agarose gel, which contained equal volumes $(0.25 \mathrm{ml})$ of A. hippikon antiserum and the monospecific antiserum. Only one of the peaks was suppressed (Fig. 5B), indicating that the superim- posed antigens were not serologically related. Of the two antigens recognized by the $A$. axanthum antiserum (Fig. 2, column 5), the common antigen in each species was identified (Fig. 2, arrows). The other antigen was determined to be present in $A$. equifetale, $A$. granularum, $A$. hippikon, and $A$. laidlawii but could not be detected in $A$. axanthum. The electrophoretic mobility of this antigen varied from $0.47(A$. equifetale) to 0.62 (A. laidlawii).

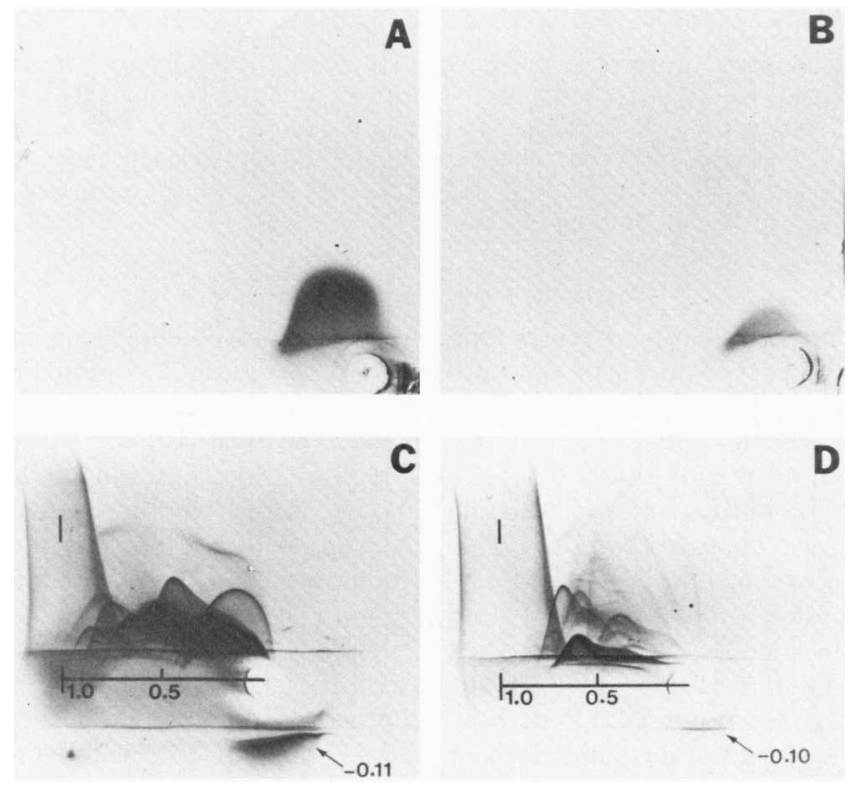

FIG. 3. Positively charged antigens shown by A. axanthum (slides A and C) and A. laidlawii (slides B and D) antigens against their respective homologous antisera. For slides $\mathrm{A}$ and $\mathrm{B}$, the anode was at the right during firstphase electrophoresis and at the bottom of the slide during second-phase electrophoresis. For slides $\mathrm{C}$ and $\mathrm{D}$, the antigen wells were near the centers of the slides, the antiserum was both above and below the antigen track, and the anode was at the left during first-phase electrophoresis and at the top during the second phase. The scales on slides $C$ and $D$ indicate the relative electrophoretic mobilities of the peaks; a value of 1.0 equaled the mobility of bovine albumin, whose peak is identified by the vertical bar at the top left corner of the slide. 


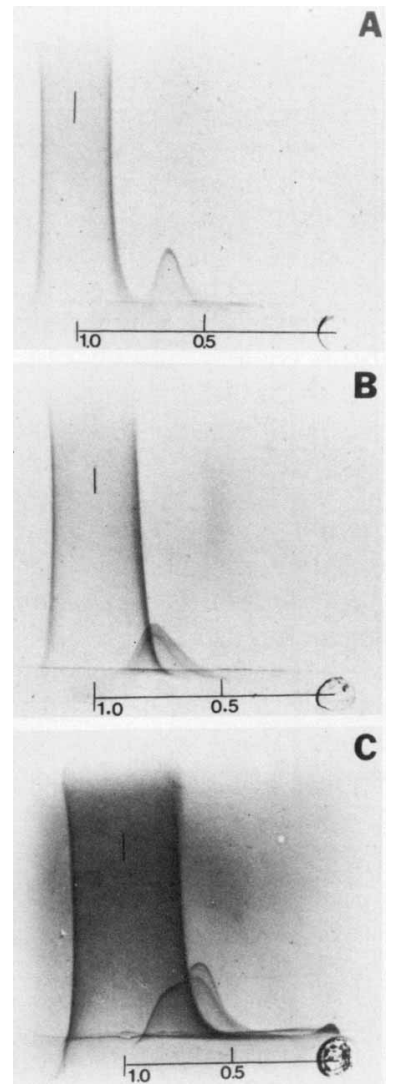

FIG. 4. Specificity of monospecific antiserum. The antigens tested were $20 \mu \mathrm{g}$ (protein) of $A$. laidlawii (A), $20 \mu \mathrm{g}$ of $A$. hippikon (B), and $20 \mu \mathrm{g}$ of $A$. laidlawii plus $20 \mu \mathrm{g}$ of $A$. hippikon (C). The antiserum used was monospecific antiserum to peak 0.72 of $A$. hippikon. Cell protein was electrophoresed in the first phase (anode to the left of the slide) and was developed against $0.25 \mathrm{ml}$ of the monospecific antiserum in the second phase (anode at the top of the slide). The scale at the bottom of each slide indicates the relative mobilities of the peaks; a value of 1.0 equaled the mobility of bovine albumin, whose peak is identified by the vertical bar at the top of the slide. The anode was to the left and top of each frame.

Controls. The agamma horse serum used in the medium did not form any precipitin lines against the antisera used in this study; this indicated that the immunized rabbits had no preexisting antibodies to horse serum antigens and that the immunogen preparations were not contaminated with agamma horse serum. When antigens of the various species were tested against antiserum produced against agamma horse serum (Table 1), no precipitin lines were observed, indicating that the antigen preparations were free of serum contamination. Therefore, we concluded that horse serum antigens were not part of the profiles observed.

\section{DISCUSSION}

Organisms in the family Acholeplasmataceae are distinguished from other organisms in the order Mycoplasmatales by the following three distinctive characteristics: (i) they do not require cholesterol for growth; (ii) their genome molecular weight is $10^{9}$; and (iii) reduced nicotinamide adenine dinucleotide oxidase is located in their membranes (18). Determination of whether an organism belongs to the family Acholeplasmataceae is not easy since the above characteristics are fairly difficult to determine (18). Alternatively, the serotype of a species can be determined, but not all Acholeplasma strains or species are readily identifiable by growth inhibition on agar (18). Our previous technique for identifying unknown Acholeplasma species was to test them by double immunodiffusion against antisera to a number of Acholeplasma species because we knew that common antigens are present in this group (8). Kirchhoff (9) presented clear evidence for the presence of common antigens in the Acholeplasmataceae, with one to three common antigens evident between strains. The closest relationship found in our study was between $A$. hippikon and A. equifetale, whereas Kirchhoff, using the less sensitive technique of double immunodiffusion, did not find that these strains were more closely related than other Acholeplasma species.

We identified a common antigen in five Acholeplasma species, and prepared a monospecific antiserum to this antigen. If this antigen proves to be specific to all Acholeplasma species and

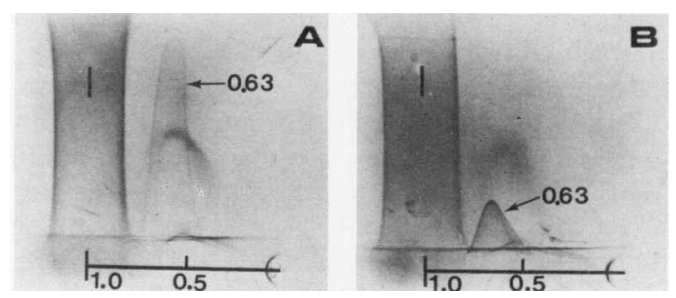

FIG. 5. Suppression of the antigenic profile of $A$. laidlawii against $A$. hippikon antiserum by addition of monospecific antiserum. A $20-\mu \mathrm{g}$ portion of cell protein was electrophoresed in the first phase (anode to the left of the slide) and developed against antiserum in the second phase (anode at the top of the slide). In slide $\mathrm{A}$ the antiserum was $0.25 \mathrm{ml}$ of $A$. hippikon antiserum, and in slide B the antiserum consisted of $0.25 \mathrm{ml}$ of $A$. hippikon antiserum plus $0.25 \mathrm{ml}$ of monospecific antiserum. The scales at the bottoms of the slides indicate the relative electrophoretic mobilities of the peaks; a value of 1.0 equaled the mobility of bovine albumin, whose peak is identified by the vertical bar at the top of each slide. The anode was to the left and top of each frame. 
not present in Mycoplasma species, it may have considerable taxonomic utility in determining whether an organism is a member of the Acholeplasmataceae. Most important, the presence of this antigen would be a positive criterion, whereas the cholesterol requirement is a negative criterion. The antigen appears to be present in a readily detectable concentration in each of the five organisms which we tested. The relative peak areas varied from 0.26 ( $A$. equifetale) to $1.00(A$. granularum $)$ in the five organisms when they were tested against one antiserum (Fig. 2, frames A5, B5, C5, D5, and E5), a result which suggests that the antigen should be readily detectable by counterimmunoelectrophoresis against the monospecific antiserum. Furthermore, the fact that we have a monospecific antiserum should permit us to fractionate the antigen by immunoabsorption (3) and determine its characteristics. One technical point of interest is the fact that a monospecific antiserum against a common component is most easily prepared by excising a peak from the antigen developed against a heterologous but cross-reacting antiserum (note that it is very difficult to detect the common antigen in the homologous profile).

The common antigen has a strikingly variable electrophoretic mobility, ranging from $0.45(A$. axanthum) to 0.72 (A. hippikon). The common antigens in the various species are serologically related but not necessarily immunologically identical since only the leading edge of the $A$. hippikon peak fused with the $A$. laidlawii peak (Fig. 4C). Electrophoretic heterogeneity has also been observed in common antigens of $M y$ coplasma arginini strains (17). This antigen was clearly located in the cytoplasmic fraction of $A$. laidlawii, and circumstantial evidence from charge shift experiments suggests that it is also a cytoplasmic component of the other organisms.

Another antigen was determined to be present in four of the five species tested but could not be identified in the $A$. axanthum profile. However, it is reasonable to believe that $A$. axanthum has this antigen since antisera to $A$. axanthum detected it in heterologous organisms. Relative mobilities varied from 0.47 ( $A$. equifetale) to 0.62 (A. laidlawii), and relative peak areas ranged from 0.2 (A. granularum) to $1.0(A$. laidlawii). Further characterization will depend upon the preparation of a monospecific antiserum.

Surveys have shown that the Acholeplasma species tested have common antigens (9). Although the close relationship between $A$. laidlawii and $A$. granularum determined by deoxyribonucleic acid-deoxyribonucleic acid homology (13) suggested that these two species might have a large number of common antigens, this is not the case. The degree of relationship between the Acholeplasma species tested in crossed immunoelectrophoresis resembled the degree of relationship shown by the glucosenegative, arginine-utilizing Mycoplasma species (16). However, the Acholeplasma species which we tested are clearly more closely related than the heterogeneous organisms classified in the genus Mycoplasma, where no evidence of common antigens among all species tested has been found $(8,16)$. It is most unlikely that a common antigen which spans all Mycoplasma species will be found (8). Although we did not specifically study membrane antigens, our antisera (prepared against whole organisms) seemed to recognize primarily cytoplasmic components (i.e., most antigens detected did not charge shift [1]). When Wroblewski and Ratanasavanh (19) compared membrane antigens of $A$. laidlawii and $A$. granularum, they found only 1 common antigen among the 12 to 15 antigens that their antisera could recognize. Thus, whatever common components exist are probably cytoplasmic.

\section{ACKNOWLEDGMENT}

This study was supported in part by Public Health Service grant AI-06720 from the National Institute of Allergy and Infectious Diseases.

\section{LITERATURE CITED}

1. Alexander, A. G., and G. E. Kenny. 1978. Application of charge shift electrophoresis to antigenic analysis of mycoplasmic membranes by two-dimensional immunoelectrophoresis. Infect. Immun. 20:861-863.

2. Axelsen, N. H., and E. Bock. 1972. Identification and quantitation of antigens and antibodies by means of quantitative immunoelectrophoresis. A survey of methods. J. Immunol. Methods 1:109-121.

3. Caldwell, H. D., and C. C. Kuo. 1977. Purification of a Chlamydia trachomatis-specific antigen by immunoadsorption with monospecific antibody. J. Immunol. 118:437-441.

4. Caldwell, H. D., C. C. Kuo, and G. E. Kenny. 1975. Antigenic analysis of chlamydiae by two-dimensional immunoelectrophoresis. I. Antigenic heterogeneity between C. trachomatis and C. psittaci. J. Immunol, 115:963-968.

5. Helenius, A., and K. Simons. 1977. Charge shift electrophoresis: simple method for distinguishing between amphiphilic and hydrophilic proteins in detergent solution. Proc. Natl. Acad. Sci. U.S.A. 74:529-532.

6. Kenny, G. E. 1969 . Serological comparison of ten glycolytic Mycoplasma species. J. Bacteriol. 98:1044-1055.

7. Kenny, G. E. 1971. Immunogenicity of Mycoplasma pneumoniae. Infect. Immun. 3:510-515.

8. Kenny, G. E. 1979. Antigenic determinants, p. 351-384. In M. F. Barile and S. Razin (ed.), The mycoplasmas, vol. 1. Cell biology. Academic Press, Inc., New York.

9. Kirchhoff, H. 1978. Acholeplasma equifetale and Acholeplasma hippikon, two new species from aborted horse fetuses. Int. J. Syst. Bacteriol. 28:76-81.

10. Kroll, J. 1969. Immunochemical identification of specific precipitin lines in quantitative immunoelectrophoresis patterns. Scand. J. Clin. Lab. Invest. 24:55-60.

11. Laurell, C. B. 1965. Antigen-antibody crossed electrophoresis. Anal. Biochem. 10:358-361.

12. Lowry, O. H., N. J. Rosebrough, A. L. Farr, and R. J. Randall. 1951. Protein measurement and the Folin phenol reagent. J. Biol. Chem. 193:265-275. 
13. Neimark, H. C. 1970. Division of Mycoplasma into subgroups. J. Gen. Microbiol. 63:249-263.

14. Pollock, M. E., and S. V. Bonner. 1969. Comparison of undefined medium and its dialyzable fraction for growth of Mycoplasma. J. Bacteriol. 97:522-525.

15. Rottem, S., M. Hasin, and S. Razin. 1973. Binding of proteins to Mycoplasma membranes. Biochim. Biophys. Acta 298:876-886.

16. Thirkill, C. E., and G. E. Kenny. 1974. Serological comparison of five arginine-utilizing Mycoplasma species by two-dimensional immunoelectrophoresis. Infect. Immun. 10:624-632.
17. Thirkill, C. E., and G. E. Kenny. 1975. Antigenic analysis of three strains of Mycoplasma arginini by two-dimensional immunoelectrophoresis. J. Immunol. 114:11071111.

18. Tully, J. G. 1979. Special features of the acholeplasmas, p. 431-449. In M. F. Barile and S. Razin (ed.), The mycoplasmas, vol. 1. Cell biology. Academic Press, Inc., New York.

19. Wroblewski, H., and D. Ratanasavanh. 1976. Etude par immunoelectrophorese bidimensionnelle de la composition membrane de quelques souches de mycoplasmes. Can. J. Microbiol. 22:1048-1053. 